\title{
A novel method for maintaining the stability of freshly cultured Mesenchymal stem cells in clinical grade injection ready state without cryopreservation
}

\author{
Mandana Mohyeddin Bonab ${ }^{{ }^{*}} \mathbb{0}$, Fatemeh Talebian ${ }^{2}$, Aida Borzabadi $^{3}$, Vahideh Nasr $^{4}$, \\ Azam Abedi Kooshlshahi' , Fahime Anisie', Ronaz Haghshenas ${ }^{1}$, Bita Shalbafan ${ }^{5}$, Ehsan Janzamin ${ }^{6}$ and \\ Saeed Shahbeigi ${ }^{7}$
}

\begin{abstract}
Background: Mesenchymal Stem Cells (MSCs) are multipotent cells with low immuonogenecity, and dynamic tissue repair potential, which explains the overwhelming attention they have attracted in regenerative therapy. One notable challenge in MSCs therapy is the bench to bed timeline of freshly cultured MSCs; it does not exceed $24 \mathrm{~h}$. For use after $24 \mathrm{~h}, \mathrm{MSC}$ need to be cryopreserved - which can preserve the cells for years - but it is a costly and damaging process. Here we introduce a method to extend the bench to bed lifetime of MSCs up to 4 days without the high cost and cell damaging effects of cryopreservation. Our method is based on preserving the MSCs in human plasma.

Methods: MSCs of 12 tissue samples - 4 adipose, 4 bone marrow and 4 Wharton's jelly- were cultured and expanded in standard conditions. Cells harvested from passage 2 or 3 were washed, centrifuged, pelleted, and re-suspended in human plasma. Cell suspensions were refrigerated $\left(5 \pm 3^{\circ} \mathrm{C}\right)$ or stored at room temperature $\left(22 \pm 3^{\circ} \mathrm{C}\right)$ in a sterile, temperature controlled room. During the next 7 days, two tubes (one from each group) were examined every $24 \mathrm{~h}$ to assess MSCs viability and growth potential. On day 3, we assessed MSC cell surface markers and its differentiation potential to adipocyte and osteocyte tissues. Results were analyzed by computing the overall mean and applying the independent-samples t-test to those means.
\end{abstract}

Results: The sample means for both cell expansion and cell viability were compared between the two "refrigerator" and "room temperature" groups. Although there was a gradual decrease in cell growth potential between the cells stored for 1 day to those stored for 7 days, we show more than $80 \%$ of the cells remain alive for up to 4 days of storage in both groups. The cells reached $80 \%$ confluency in under 20 days for all samples stored up to 4 days. No significant differences were observed between the two groups (room temperature and refrigerator stored). The differentiation potential to adipocyte and osteocyte tested on day 3 were positive in all samples. The analysis of cell surface markers tested on day 3 were positive for CD90, CD105, CD73 and negative for CD34, CD45 and HLA-DR.

Conclusion: We present a method of MSC culture medium using human plasma that can preserve their viability and growth potential for up to 4 days in both room and refrigerator temperatures without losing their stemness characteristics (we recommend use of $5 \pm 3^{\circ} \mathrm{C}$ ). This novel method will allow rapid expansion and therapeutic use of MSCs.

\footnotetext{
*Correspondence: mandanamohyeddin@gmail.com

1 Sinacell Research and Production Co, Tehran, Iran

Full list of author information is available at the end of the article
} permits use, sharing, adaptation, distribution and reproduction in any medium or format, as long as you give appropriate credit to the original author(s) and the source, provide a link to the Creative Commons licence, and indicate if changes were made. The images or other third party material in this article are included in the article's Creative Commons licence, unless indicated otherwise in a credit line to the material. If material is not included in the article's Creative Commons licence and your intended use is not permitted by statutory regulation or exceeds the permitted use, you will need to obtain permission directly from the copyright holder. To view a copy of this licence, visit http://creativecommons.org/licenses/by/4.0/. 
Since the cells can be maintained in clinical grade, injection ready state for several days, they can be transported across the globe.

Keywords: Mesenchymal stem cells (MSCs), Storage, Plasma

\section{Introduction}

Mesenchymal stem cells (MSCs) have an innate capacity for multipotent differentiation, giving them invaluable potential for clinical applications, therapeutic uses and regenerative medical practice. Clinical use of MSC was reported in 1995 [1] and has been become an increasingly popular option over the decades [2, 3]. MSC have been harvested and expanded in culture for treatment of many degenerative diseases both autologously and allogenically. To therapeutically use these cells for patients, MSC must be kept in a clinical grade medium after expansion and harvesting. This medium must maintain the biological characteristics of the cells until they are administered to the patient. The standard method suggested and used to date is sterile clinical-grade injectable normal saline with a small percentage of human serum albumin (2-5\% based on various studies) [4-6]. This cell suspension must be injected within $24 \mathrm{~h}$, otherwise MSCs begin to lose their biological characteristics. The standard method for long term storage of these cells is cryopreservation. Cryopreservation is a valuable method in stem cell research and regenerative medicine. However, there are some risks associated with cryopreservation, which include:

1. Decreased survival rate: Cells must be taken from a metabolic state to a frozen state for storage and then from a frozen state back to a metabolic state for use. During this transition, intracellular ice crystals could form and damage the cell $[7,8]$.

2. Use of DMSO: Using DMSO when cryopreserving the cell will prevent formation of intracellular crystals. However, DMSO is cytotoxic for cells in their metabolic state (an effect that could be realized between thawing time and washing the cells) [9-11].

3. This is a time consuming and expensive method. The freezing and thawing procedure causes considerable decline in cell viability.

Since 1924, when MSC was discovered, they have garnered substantial attention. This does not come as a surprise, because MSC have the potential to differentiate into mesodermal cell lineages such as adipocytes, osteocytes and chondrocytes. They can also trans-differentiate into cells originating from the ectodermal and endodermal lineage including neural cells and hepatocytes $[12,13]$. These cells have the potential for immunomodulation, anti-inflammatory regulation, growth factor production and anti-apoptotic effects [14-17]. To date, most therapies based on stem cells use cryobanked cells. Recent studies suggest the freeze-thawing process of cryopreserved cells could adversely affect their therapeutic potential compared to freshly cultured cells [18]. In 2000, Bennet et al. [19] reported the results of their islet transplants in type I diabetic patients. They discovered when islet cells are exposed to blood, instant blood mediated inflammatory reaction (IBMIR) is triggered. This is a phenomenon characterized by activation of the complement system, coagulation and platelet consumption [20]. This means injected stem cells become targets for lysis via the complement system and thus their therapeutic effect is diminished. Moll et al. [21] has compared the therapeutic, immunomodulatory and blood regulatory potential of freeze-thawed versus freshly cultured MSCs. They demonstrated that invitro, freeze-thawed MSCs are more prone to lysis via the complement system and the IBMIR phenomenon when compared to freshly cultured MSCs. Also, compared to the freshly cultured MSCs, freeze-thawed MSCs displayed a diminished response to pro-inflammatory cytokines and decreased anti-inflammatory cytokine secretion profile. Another immunomodulatory factor they analyzed, is expression and enzymatic activity of IDO. IDO is an immunosuppressive enzyme that activates Treg cells. Twenty four hours after stimulation, expression of this enzyme was dramatically higher in freshly cultured MSCs compared to their freeze-thawed counterpart. However, 7 days after stimulation with IFN- $\gamma$, the activity and levels of secreted IDO was comparable between the two therapeutic groups. Results of patient follow up were as follows: 7 freeze-thaw injected patients showed $71 \%$ response, while the 5 fresh culture MSC injected patients, had $100 \%$ response. The authors observed no long-term engraftment issues for either group. Studies have shown that during the freeze-thaw process, $20-30 \%$ of cell viability is irreversibly compromised. Notably, freeze-thawed cells have a diminished immunomodulatory potential due to up-regulation of heatshock response and disrupted IFN- $\gamma$ function (http:// stemcellas says.com/2013/01/failu re-mesenchymalstem-cells-gvhd-devil-cell-prep/) [22]. Transfusion of Freeze-thawed MSC in mice yields considerably shorter viability compared to freshly prepared MSC. 
This limitation of thawed cells is not permanent; if cells are cultured for $24 \mathrm{~h}$ after thawing, they regain their potency [23]. Therefore, when using MSCs for clinical purposes, freeze-thawed cells should be kept in in-vitro culture conditions until they regain their full potential before in-vivo therapeutic application.

In this paper, we introduce a method to maintain fully functional cultured MSC at least 4days, forgoing the expense and cellular damage caused by freezing. We used $\mathrm{AB}+$ human plasma medium to maintain freshly cultured cells for several days and compared their biological characteristics to cells maintained in normal saline containing Human Serum Albumin (HSA) in the refrigerator and at room temperature.

\section{Materials and methods}

Mesenchymal stem cells (MSCs) were isolated from 4 bone-marrow, 4 Wharton's jelly placenta cord and 4 adipose tissue sources. Bone-marrow cells were extracted from Multiple Sclerosis (MS) patients and adipose tissue was extracted from Acute Respiratory Distress Syndrome (ARDS) patients who were candidates for mesenchymal stem cell therapy. These samples were taken from a pool of stem cells prepared for therapy. Because the purpose was evaluating the stability of patient cells for patient treatment, we worked on samples taken for this exact use. Placenta cord samples (as allogeneic source for therapeutic use) were taken from infants from cesarean births. Informed consent forms were filled by patients and mothers at time of sample collection.

\section{Ethical considerations}

The study design and the informed consents for adipose mesenchymal stem cells were approved by the Ethics committee of Baqiyatallah University of Medical Sciences (ethics code: IR.BMSU.REC.1393.32). For bone marrow MSC, approved by Tehran University of Medical Sciences (TUMS) and Shahid Beheshti University of Medical Sciences (ethics code: IR.SBMU.REC.1395.82). Wharton's jelly was obtained from SinaCell. SinaCell provides questionnaires and informed consent papers for all donors at the time of collection.

\section{Normal saline method}

Five bone marrow, 5 Wharton's jelly cord cells and 4 adipose tissue samples were collected for this method. These 14 samples were isolated and expanded using standard methods [24-27]. Four million MSCs were isolated from each sample at the time of stem cell therapy. All cells were taken from passages 2 or 3. Cells were kept in normal saline solution supplemented with $2.5 \%$ HSA (prepared by the Iranian Blood Transfusion Organization) and $1 \mathrm{U} / \mathrm{ml}$ heparin and prepared as an injection ready suspension. We took a sample from these cell suspensions to test cell viability at collection time (zero hour). This sample was transferred to two sterile polystyrene tubes, each containing $2 \times 10^{6} \mathrm{cells} / \mathrm{ml}$. One of the tubes was kept in the refrigerator $(5+/-3$ degrees) and the other at room temperature ( $22+/-3$ degrees). Each sample was tested for viability at $6,12,18$ and $24 \mathrm{~h}$ after collection time.

\section{Plasma method}

Four of each of the following samples were collected: bone marrow, Wharton's jelly and adipose tissue. These 12 samples were isolated and cultured using standard methods. Twelve sterile tubes were used for each sample. Collected cells were used to evaluate stability of first three passages. We prepared a 25 million MSC $\left(2 \times 10^{6}\right.$ cells $\left./ \mathrm{ml}\right)$ suspension in human $A B+$ plasma medium (prepared by the Iranian Blood Transfusion Organization). We then transferred $1 \mathrm{ml}$ of this suspension to each of the 12 sterile tubes. Six tubes were transferred to the refrigerator $(5+/-3$ degrees) and 6 were placed in room temperature $(22+/-3$ degrees) in a temperature controlled clean room. On days 1 to 5 and day 7 , one tube from the refrigerator and one tube from the room temperature were tested for both cell viability and in-vitro growth potential. Cell surface markers, adipocyte and osteocyte differentiation potential of each sample in both temperature conditions were tested on day 3. Two tubes from the 3 cell sources was tested for differentiation potential at both temperature conditions on day 5.

Each sample was tested for adipocyte and osteocyte differentiation potential. They were also stained for the following cell surface markers CD34 (ExBio IP-664-T025), CD45 (BD Biosciences 560,976), CD73 (cBiosciences 11-0739-42), CD90 (ExBio IF-652-100 T), CD105 (ExBio IP-298-T025), and HLA-DR (Immunostep PP5.5-100 T) (flowcytometric analysis) at harvest time before they were considered for this study. Differentiation of these cells to adipocyte and osteocyte was confirmed with Oil red $\mathrm{O}$ and Alizarin red staining respectively. MSC were identified as cells that were $95 \%$ or more positive for CD73, CD90 and CD105 markers and less than 2\% negative for CD34, CD45, and HLA-DR markers. Viability tests were performed by day exclusion method using Trypan Blue.

To test for growth potential, cells were cultured ina medium containing 10\% FBS (ATOCEL ATSM-11,15) and DMEM Low Glucose with Glutamine (Biowest A0101) without antibiotics in 6-well cell culture plates under GMP grade conditions. Culture medium were replaced with fresh medium every 3 days until cell 


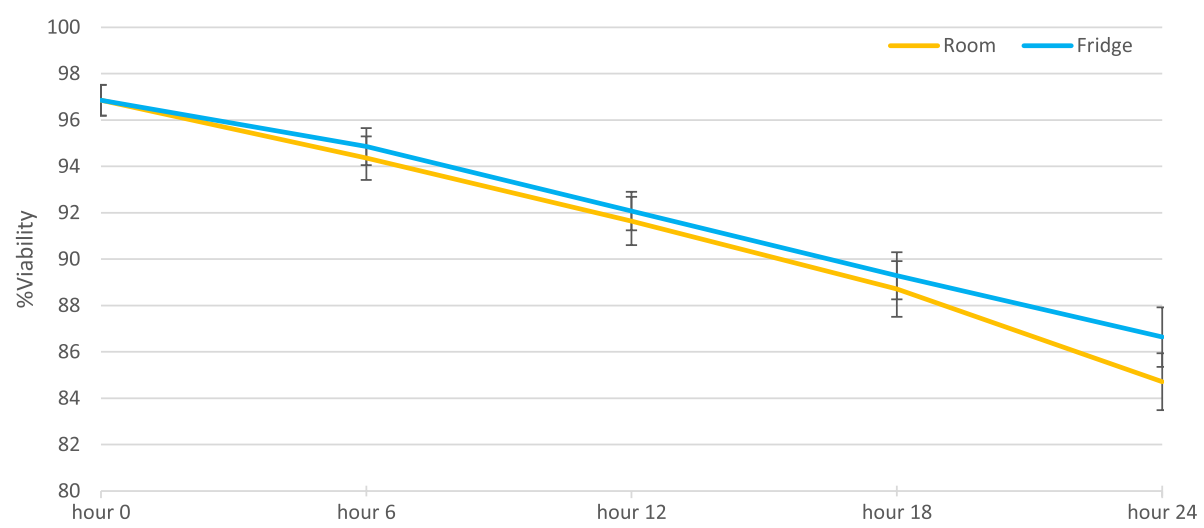

Fig. 1 The mean of cell viability of 14 samples stored for $24 \mathrm{~h}$ in normal saline solution in room and refrigerator temperature
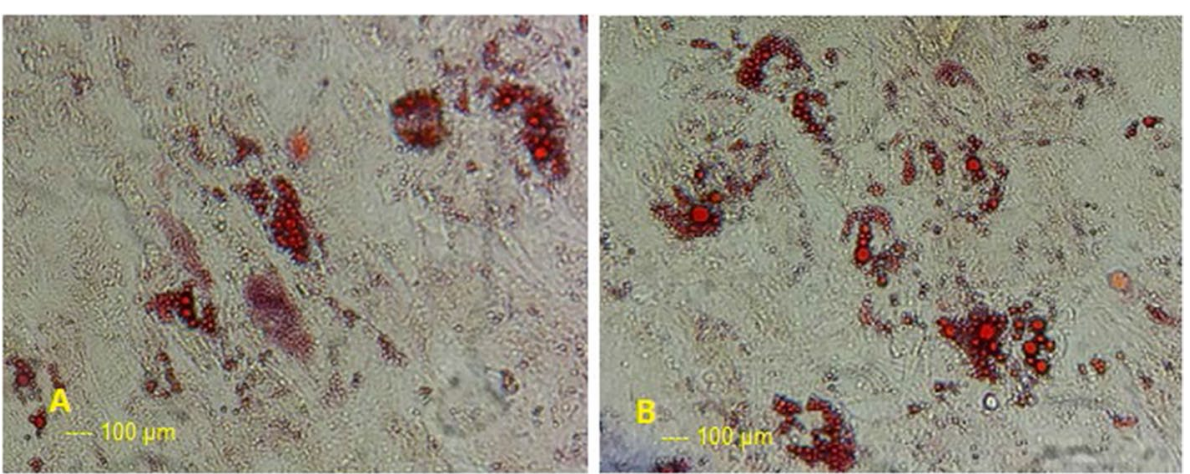

Fig. 2 Oil red O staining showing fat drops in adipocytes of differentiated MSCs following 3 weeks of culture in adipocyte differentiation medium Pictures taken after $18 \mathrm{~h}$ of storage in normal saline. A Refrigerator temperature, B Room temperature

confluency reached over $80 \%$. Growth potential was considered positive if the cells reached more than $80 \%$ confluency within 20 days of culture. To evaluate the cell surface markers CD34, CD45, CD73, CD90, CD105 and HLA-DR, we used a Flow cytometer.

To test for stem-ness of these cells, their differentiation potential was evaluated in specific differentiation medium for adipocyte and osteocyte. To confirm the cell differentiation, adipocyte and osteocyte cultures were stained by Oil red $\mathrm{O}$ and Alizarin red staining respectively.

\section{Statistical analysis}

Statistical analyses were performed using Microsoft excel software. We used the T-test to measure viability of cells kept in normal saline and to compare the mean viability and growth potential of cells kept in plasma at both temperatures. We evaluated the effect of viability for cells kept in normal saline and growth potential of cells kept in plasma based on the tissue of origin using multivariate variance One-way ANOVA comparisons (post Hoc) test. $P<0.05$ was considered to be statistically significant.

\section{Results}

Viability tests for cells suspended in normal saline (normal saline $+2.5 \% \mathrm{HSA}+1$ heparin $\mathrm{U} / \mathrm{ml}$ ) performed at $6 \mathrm{~h}$ intervals (over $24 \mathrm{~h}$ ) in refrigerator and room temperature conditions did not show any significant difference using independent sample $\mathrm{T}$ test. Figure 1 shows that the percent of viable cells decreases slowly (demonstrated by the mild downward slope) and maintains more than $80 \%$ viability for $24 \mathrm{~h}$ and the average viability in refrigerator and room temperature conditions are 84 and $86 \%$ respectively for these samples.

These cells were cultured in adipocyte and osteocyte differentiation medium, they maintained their growth and differentiation capabilities at 18 and $24 \mathrm{~h}$ time points, both in the refrigerator and at room temperature (Figs. 2 and 3). We observed no growth in any of the samples after the second day. These results clearly show normal saline suspension cannot maintain these cells for more 

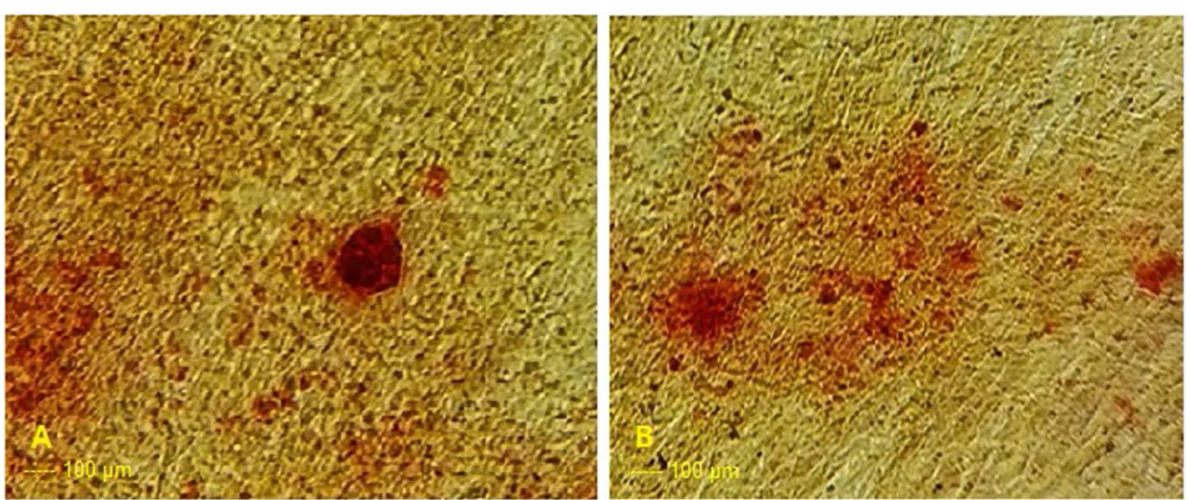

Fig. 3 Alizarin red staining showing calcium deposits in osteocytes of differentiated MSCs following 3 weeks of culture in osteocyte differentiation medium. Pictures taken after $18 \mathrm{~h}$ of storage in normal saline. A Fridge, B Room temperature

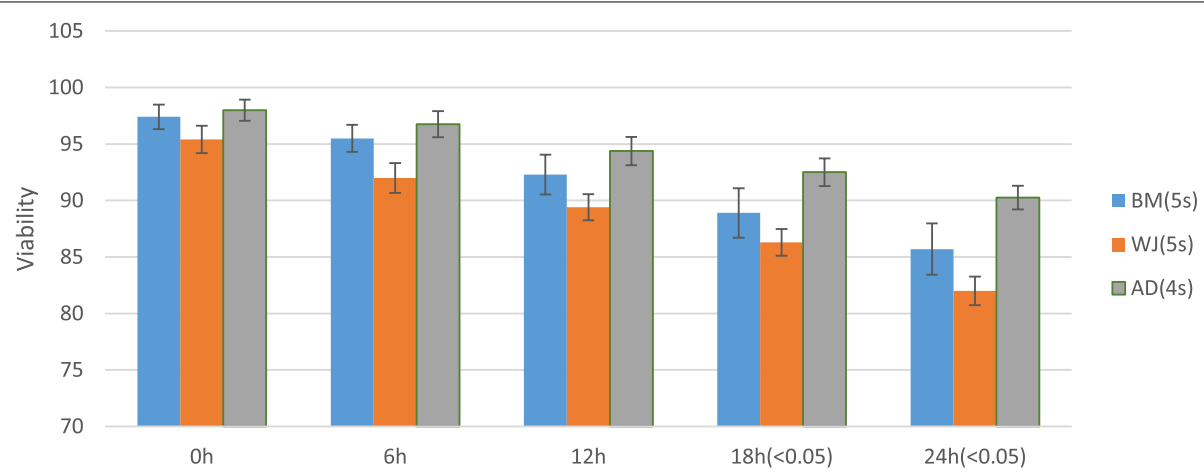

Fig. 4 Comparison the mean of cell viability $\geq 80 \%$ between different cell origin strored for $24 \mathrm{~h}$ in normal saline

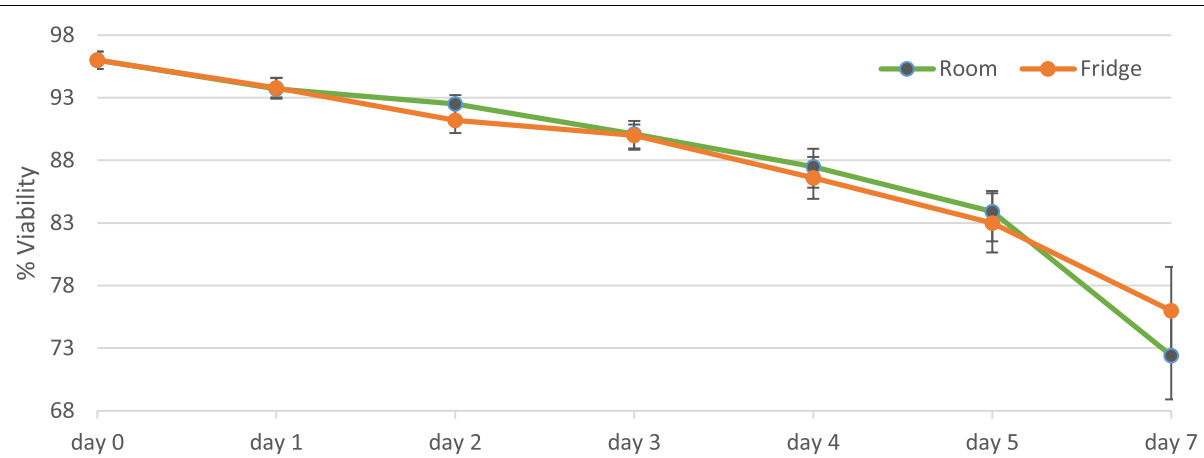

Fig. 5 The mean of cell viability of 12 samples stored for 7 days in human AB+ plasma in room and refrigerator temperatures

than $24 \mathrm{~h}$. The mean sample cell viability for both temperatures (based on their cell sources) in normal saline and using multivariate variance One-way ANOVA comparisons (post Hoc) test, showed no significant difference at 6 and $12 \mathrm{~h}$. However, at 18 and $24 \mathrm{~h}$, cells isolated from adipose tissue had better viability compared to cells isolated from other sources (Fig. 4). The cells maintained in human $\mathrm{AB}+$ plasma solution (refrigerator and room temperature conditions) over the period of a week, did not show a significant difference in viability over time. As you can see in Fig. 5, viability of cells in both temperatures had a slight decline each day, but remained above $80 \%$ until the fifth day. After day 5 , cell viability dropped to around $70 \%$. Growth potential of cells suspended in 


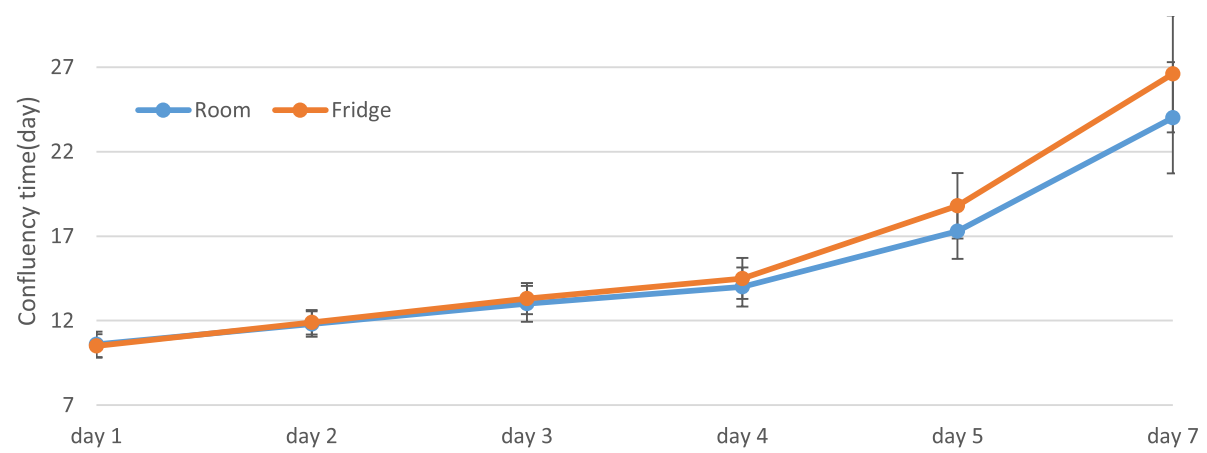

Fig. 6 The mean time for cell confluency $\geq 80 \%$ stored in human $A B+$ plasma for 7 days (each 12 samples) in room and refrigerator temperatures

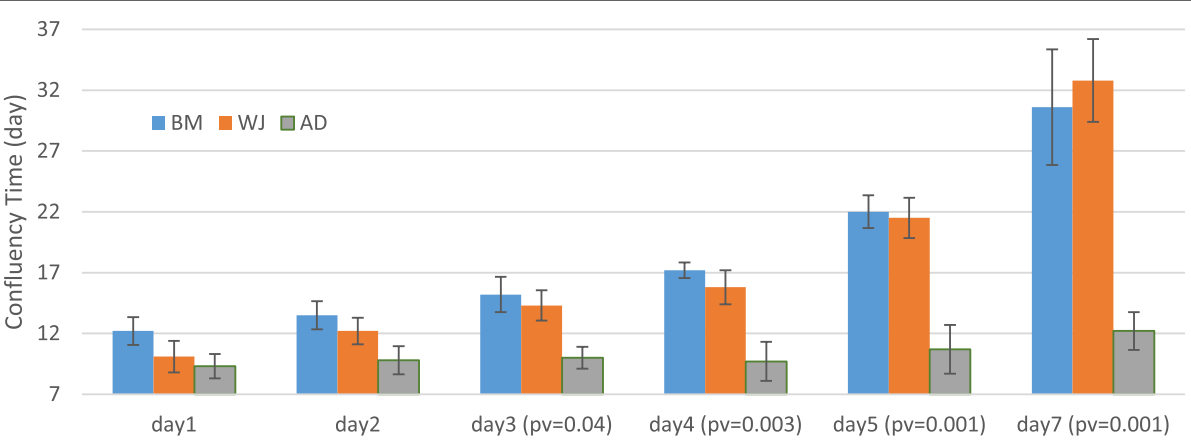

Fig. 7 Comparison of the mean time of cell confluency $\geq 80 \%$ between 3 different cell origis (each 4 samples) stored for 7 days in human $A B+$ plasma. $\mathrm{AD}=$ Adipose, $\mathrm{BM}=$ Bone Marrow, $\mathrm{WJ}=$ Wharton's jelly, $\mathrm{P} . \mathrm{V}=p$ value

human $\mathrm{AB}+$ plasma solution was tested based on confluency (above $80 \%$ ) at 20 days for both temperatures. We did not observe any significant difference over this period (Fig. 6). Confluency of $80 \%$ or more was noted for cells cultured up to 5 days, however, the growth potential of day 7 cells did not have such favorable results and in some samples they did not have acceptable growth rates.

The mean growth potential of cells (both temperatures) suspended in human AB+ plasma, based on their cell sources was statistically analyzed for multivariate variance using the One-way ANOVA comparisons (post Hoc) test. Growth potential of these cells showed no significant difference on days 1 and 2 . However, after the second day, we observed that cells isolated from adipose tissue had notably better growth rates compared to cells isolated from Wharton's jelly and bone marrow (Fig. 7).

Results of differentiation from cells maintained in $\mathrm{AB}+$ plasma for both temperature conditions on days 3 and 5 demonstrated these cells maintain their differentiation potential to adipocyte and osteocytes (Figs. 8 and 9).

Results of cell surface markers were positive for CD90, CD105 and CD73 (more than 95\%) and negative for CD34, CD45 and HLA- (less than 2\%) (Fig. 10).

\section{Discussion}

Stem cell therapy, as a field of study and a promising clinical treatment, is growing exponentially. Among stem cells, MSCs have distinguished themselves as cells with the greatest applied potential because of their unique combination of characteristics including multipotency, accessibility, culture competency, and low immunogenicity, immunomodulatory and tissue repair potential [2830]. One of the most important issues in cell therapy is successful maintenance of cells from bench to bedside. It is imperative to have a standard medium suitable for maintaining these cells for an adequate amount of time until they reach the bedside. This must be done without any significant change in the shape or characteristics of these cells before injection. Therefore it is crucial to determine the shelf-life where all their potentials are maintained [25, 31]. To date, the best method for long term maintenance of cells and live tissue samples is cryopreservation. In cell therapy today, if we do not want to freeze the cells, we must treat the patients with the cells on the day cells are harvested. These cells are kept in HSA supplemented normal saline solution and we have shown the extent of their stability in this study (up to $24 \mathrm{~h}$ ). Many times it is not possible to treat the patient on the 

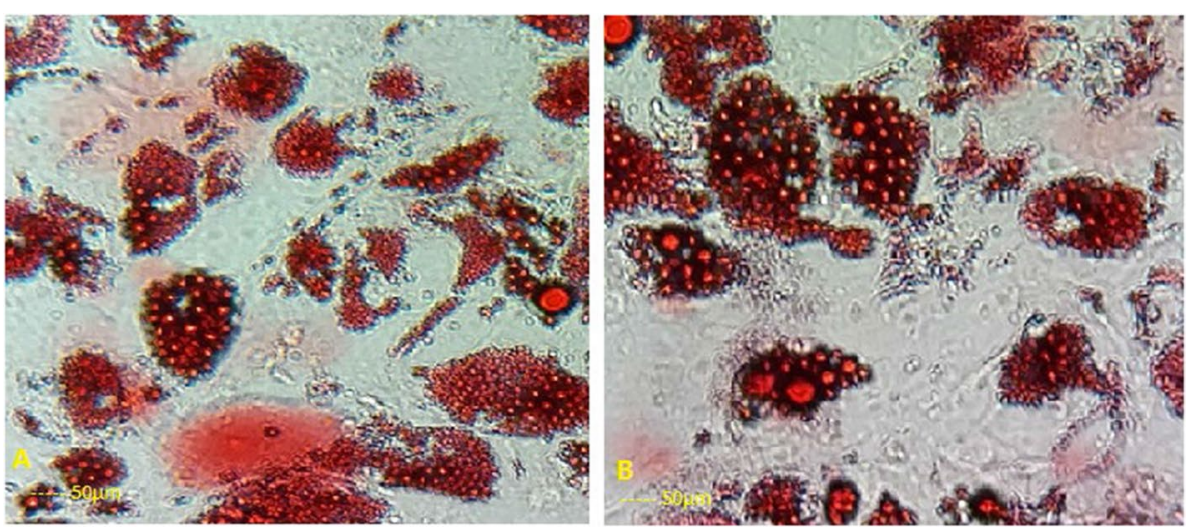

Fig. 8 Oil red O staining showing fat drops in adipocytes of differentiated MSCs following 3 weeks culture in adipocyte differentiation medium. Pictures taken after storage for 3 days in $A B+$ human plasma. A Refrigerator temperature, B Room temperature
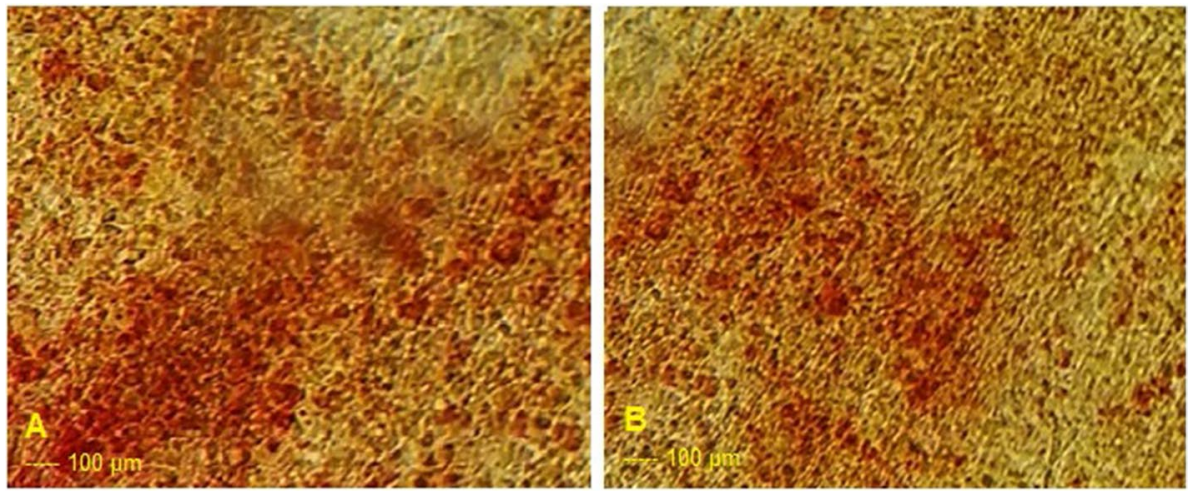

Fig. 9 Alizarin red staining showing calcium deposits in osteocytes of MSCs following 3 weeks culture in osteocyte differentiation medium. Picture taken after storage for 3 days in in $\mathrm{AB}+$ human plasma. A fr refrigerator idge, $\mathbf{B}$ Room temperature

same day due to unanticipated medical issues, distance or other problems for the patient or physician. Under such conditions, the cells must be frozen, but doing so for a few days is costly and will compromise the quality of the cells. Therefore, finding a way to maintain these cells for a few days will be financially and medically invaluable. Furthermore, studies show that fresh cells (not frozen previously) yield better results in therapeutic applications [32]. In his 2013 report, Jacques Galipeau showed that freeze-thawed cells are functionally impaired, as demonstrated by the therapeutic effects, compared to treatment with freshly isolated cells [33]. A study using human hepatocytes after cryopreservation observed metabolic defects in these cells. This study reported that the cryopreserved hepatocytes had lost most of their capacity for adherence to surfaces. Adhesion plays a defining role in successfully transfusing these cells [34]. In hematopoietic stem cell transplantation, researchers have reported use of fresh cells (not cryopreserved cells) in transplant patients' results in faster engraftment, less neutropenic fever, and shorter hospitalization time. Chinnaduria et al. [35] found that cryopreserved MSC adhesive capacity to fibronectin was reduced by $40 \%$ compared to freshly cultured MSC. Cryopreserved MSC binding defect compared to fresh MSC was even greater when adhering to endothelial cells (up to 80\%). This observation is consistent with the $60 \%$ reduction in cytoskeletal F-actin observed in thawed cells. They also showed that while thawed MSC were not detectable after injection, freshly isolated human MSCs were detectable up to $24 \mathrm{~h}$ after injection into murine liver.

One of the important aspects of MSCs is their immunomodulatory function. Many researchers have explored this capacity in freeze-thawed MSC versus freshly cultured MSCs. They found thawed MSCs have significantly reduced viability, substantially diminished capacity to inhibit in vitro $\mathrm{T}$ cell proliferation and decreased sensitivity to IFN- $\gamma$ compared to freshly isolated cells. The 


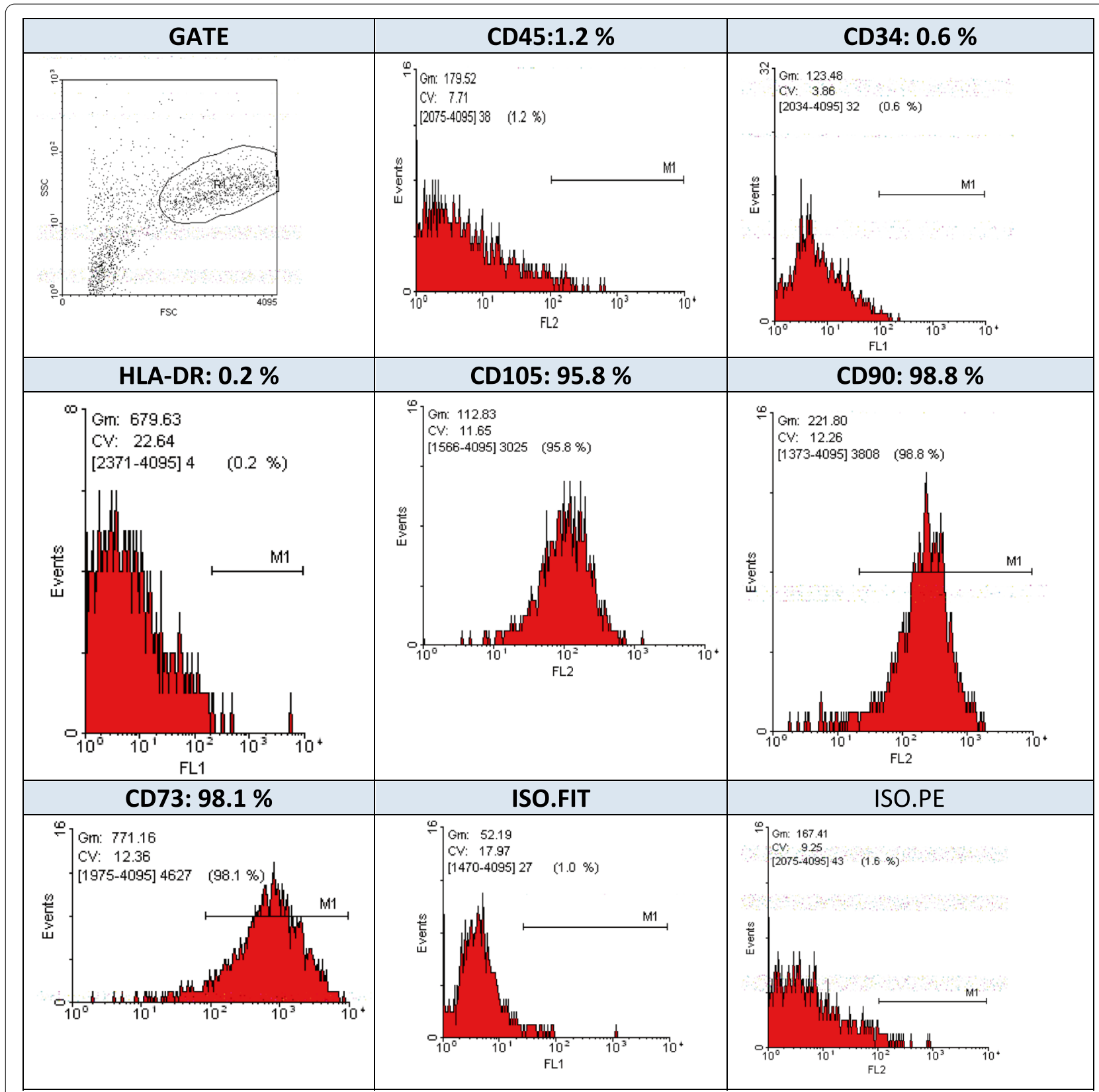

Fig. 10 MSC immunophenotyping after 3 days storage in $A B+$ human plasma

thawed cells showed a relative unresponsiveness to both pro inflammatory and anti-inflammatory cytokine signals [21, 36]. Researchers discovered once these thawed cells are cultured for $24 \mathrm{~h}$, they regain their immunomodulatory capacities. Therefore, when cryopreserved cells are thawed, it is advisable they be cultured for a certain period of time before they are injected into patients. This finding clearly shows there is a difference between freshly cultured and freeze- thawed MSCs. It is important to consider this matter when treating patients with stem cells.
To address this issue, we sought to find a cell medium that would allow longer viability and functionality for freshly isolated and cultured MSC. Our medium of choice was human $\mathrm{AB}$ positive plasma. First, it has a human origin, which resolves the animal to human contamination issues. Second, we used AB positive plasma because it lacks blood type antibodies. Finally, plasma is the best medium for preserving the natural state of cells.

Our results show that MSCs isolated from bone marrow, adipose tissue and Wharton's jelly preserve their 
stemness in $\mathrm{AB}+$ plasma medium whether they are kept in the refrigerator or at room temperature conditions. We believe MSCs isolated from adipose tissue preserve their proliferative ability better than MSC cells isolated from bone marrow and Wharton's jelly. This greater potency for expansion in culture conditions has been noted in other studies [37]. The pattern of expansion for MSCs isolated from Bone marrow and Wharton's jelly is similar but shows a more pronounced drop in proliferation relative to adipose tissue isolated MSCs over time. $\mathrm{AB}+$ plasma is a suitable candidate for keeping these cells for at least 4 days because it has no adverse effect on their biological characteristics and capabilities. This finding will prove invaluable for therapeutic use of these cells.

MSC cells must first be isolated from their source, cultured, expanded and harvested. If the patient and clinical conditions are favorable and transfusion is possible on the same day cells are harvested, they can be suspended in normal saline solution supplemented with $2.5 \% \mathrm{HSA}$ and $1 \mathrm{U} / \mathrm{ml}$ heparin. As long as this solution is injected to the patient within $18 \mathrm{~h}$, the cells will retain their viability, biological characteristics and growth potential in the body. Although these cells maintain their growth and differentiation potential in normal saline conditions for $24 \mathrm{~h}$, considering the decrease in viability to below $80 \%$ (especially for cells isolated from bone marrow and Wharton's jelly), it is more reasonable to perform the transfusion within $18 \mathrm{~h}$. We also tested a few samples with suspension in $5 \%$ HSA. The results were similar to cells suspended in $2.5 \%$ HSA (Data not shown).

If it is not possible to inject cells within $24 \mathrm{~h}$ after MSCs are harvested, the cells can be kept in AB+ human plasma for at least 4 days without compromising their biological characteristics and viability.

Our findings show that average viability and proliferative potential of cells in this medium remain above the acceptable range (viability of more than $80 \%$ and cell confluency above $80 \%$ within 20 days), however, some samples showed a decrease in these characteristics after 4 days. Perhaps MSCs isolated from adipose tissue can be kept in plasma for up to 7 days. Furthermore, although it is possible to keep these cells in plasma medium under refrigerator and room temperature conditions, we suggest cells be kept in refrigerator conditions $(5+/-3)$ because conditions are better maintained. However, keeping them in room temperature for the allotted time period is acceptable.

\section{Limitation \& Further Studies}

For the plasma method we tested MSC surface markers for all samples on day 3. Unfortunately we did not test all the samples on other days. We selected a few samples and tested that limited number. Although we do not believe this will change the outcome, it would have been better to test all samples on day 4 as well. To further confirm the findings of this study, these MSCs can be evaluated for immunomodulatory capabilities and efficacy using in vitro tests on day 4 .

\section{Conclusion}

This study evaluated the effect of time and temperature on MSCs stored in two mediums. These cells maintain their viability, growth and proliferative potential for $24 \mathrm{~h}$ in normal saline. In $\mathrm{AB}+$ plasma, both in the refrigerator and room temperature conditions, they maintained their characteristics for at least 4 days. Maintaining these cells in normal saline for $24 \mathrm{~h}$ has been reported previously. This is the first study to evaluate ex-vivo expanded MSCs prepared for patient transfusion in $\mathrm{AB}+$ plasma. We have demonstrated that cells maintain their normal capabilities and are in transfusion ready condition for up to 4 days when suspended in $A B+$ human plasma.

We are the first to report this novel method for maintaining freshly cultured MSCs in clinical grade injection ready state for more than $24 \mathrm{~h}$. The implications for this finding are astounding. This will make stem cell therapy much more accessible. It will decrease the cost considerably, since cryopreservation can be eliminated in many cases. It will also make it possible to establish a network for sharing and transferring injection ready MSCs globally.

\section{Abbreviations}

ANOVA: Analysis of variance; ARDS: Acute Respiratory Distress Syndrome; CD: Cluster of differentiation; DMEM: Dulbecco's Modified Eagle's medium; DMSO: Dimethyl sulfoxide; FBS: Fetal bovine serum; GMP: Good manufacturing practices; HAS: Human serum Albumin; HLA-DR: Human leukocyte antigen- D related; IDO: Indoleamine 2,3-dioxygenase; IFN- $\gamma$ : Interferon-gama; MS: Multiple Sclerosis; MSCs: Mesenchymal Stem Cells; Treg:T regulatory.

\section{Acknowledgements}

Not Applicable.

\section{Authors' contributions}

MMB was the Project supervisor. She also performed experiment design, many of the experimental procedures including cell culture, trouble shooting and manuscript preparation. FT assisted with Manuscript preparation and data analysis. AB performed Statistical analysis and was instrumental in patient interaction. VN supplied the Placenta and permission of its use. AAK Performed experimental procedures and cell culture. FA Performed experimental procedures and cell culture. RH Performed experimental procedures and cell culture. BS supplied MSC and contributed to patient interaction. EJ performed flowcytometery analysis. SS supplied MSC and contributed to patient interaction.

\section{Availability of data and materials}

The datasets generated during and/or analyzed during the current study are available from the corresponding author upon reasonable request. 


\section{Declarations}

\section{Ethics approval and consent to participate}

The study design and the informed consents for adipose mesenchymal stem cells were approved by the Ethics committee of Baqiyatallah University of Medical Sciences (ethics code: IR.BMSU.REC.1393.32). For bone marrow MSC, approved by Tehran University of Medical Sciences (TUMS) and Shahid Beheshti University of Medical Sciences (ethics code: IR.SBMU.REC.1395.82). Wharton's jelly was obtained from SinaCell. Sina cell provides questionnaires and informed consent papers for all donors at the time of collection.

\section{Consent for publication}

Not Applicable.

\section{Competing interests}

The authors declare no competing interests.

\section{Author details}

${ }^{1}$ Sinacell Research and Production Co, Tehran, Iran. ${ }^{2}$ Department of Pathology, Ohio state University, Columbus, OH, USA. ${ }^{3}$ Shohada Abeik Hospital, Tehran, Iran. ${ }^{4}$ Shahid Beheshti University of Medical Sciences, Tehran, Iran. ${ }^{5}$ Labbafinezhad Hospital, Tehran, Iran. ${ }^{6}$ Azma cell and tissue Laboratory, Tehran, Iran. ${ }^{7}$ Ghandhi Hospital, Tehran, Iran.

Received: 11 April 2021 Accepted: 23 September 2021

Published online: 19 October 2021

\section{References}

1. Lazarus HM, Haynesworth SE, Gerson SL, Rosenthal NS, Caplan Al. Ex vivo expansion and subsequent infusion of human bone marrow-derived stromal progenitor cells (mesenchymal progenitor cells): implications for therapeutic use. Bone Marrow Transplant. 1995;16:557-64.

2. Squillaro T, Peluso G, Galderisi U. Clinical trials with Mesenchymal stem cells: an update. Cell Transplant. 2016;25:5.

3. Galipeau J, Sense'be L. Mesenchymal stromal cells: clinical challenges and therapeutic opportunities. Cell Stem Cell. 2018;22(6):824-33.

4. Freitag J, Ford J, Bates D, Broyd HA, Wang Y, Cicuttini F, et al. Adipose derived mesenchymal stem cell therapy in the treatment of isolated knee chondral lesions: design of a randomised controlled pilot study comparing arthroscopic microfracture versus arthroscopic microfracture combined with postoperative mesenchymal stem cell injections. BMJ. 2015;5(12):e009332.

5. Mohamadnejad M, Alimoghaddam K, Mohyeddin-Bonab M, Bagheri M, Bashtar M, Ghanaati $\mathrm{H}$, et al. Phase 1 trial of autologous bone marrow Mesenchymal stem cell transplantation in patients with decompensated liver cirrhosis. Arch Iranian Med. 2007;10(4):459-66.

6. Mohyeddin Bonab M, Sahraian MA, Aghsaie A, Ahmadi Karvigh S, Hosseinian M, Nikbin B, et al. Autologous Mesenchymal stem cell therapy in progressive multiple sclerosis: an open label study. Curr Stem Cell Res Ther. 2012;7:407-14.

7. Zhmakin Al. Biological effects of low temperature, fundamentals of cryobiology. Berlin: Springer; 2009.

8. Toner M. Nucleation of ice crystals inside biological cells. JAI Press Ltd.; JAI Press Inc; 1993

9. Arakawa T, Carpenter JF, Kita YA, Crowe JH. The basis for toxicity of certain cryoprotectants: a hypothesis. Cryobiology. 1999;27:247-68.

10. Fahy GM, Lilley TH, Linsdell H, Douglas MS, Meryman HT. Cryoprotectant toxicity and cryoprotectant toxicity reduction: in search of molecular mechanisms. Cryobiology. 1990;27(3):247-68.

11. Norkus M, Kilmartin L, Fay D, Murphy MJ, ÓLaighin G, Barry F. The effect of thmprature elevation on cryopreserved mrsrnchymal stem cells. CryoLetters. 2013;34(4):349359.

12. Theise ND, Badve S, Saxena R, et al. Derivation of hepatocytes from bone marrow cells in mice after radiation-induced myeloablation. Hepatol. 2000;31:235-40.

13. Theise ND, Nimmakayalu M, Gardner R, et al. Liver from bone marrow in humans. Hepatol. 2000;32:11-6.
14. Baron F, Storb R. Mesenchymal stromal cells: a new tool against graftversus-host disease? Biol Blood Marrow Transplant. 2012;18:822-40.

15. Wang $S$, Zhu R, Li H, Li J, Han Q, Zhao RC. Mesenchymal stem cells and immune disorders: from basic science to clinical transition. Front Med. 2019:13(2):138-51.

16. Mizukami A, Swiech K. Mesenchymal stromal cells: from discovery to manufacturing and commercialization. Stem Cells Int. 2018;2018:4083921.

17. Plessers J, Dekimpe E, Van WM, et al. Clinical-grade human multipotent adult progenitor cells block CD8+ cytotoxic T lymphocytes. Stem Cells Transl Med. 2016:5:1607-19.

18. Dave Ch, McRae A, Doxtator E, H J Mei Sh, Sullivan K, Wolfe D, Champagne J, McIntyre L. Comparison of freshly cultured versus freshly thawed (cryopreserved) mesenchymal stem cells in preclinical in vivo models of inflammation: a protocol for a preclinical systematic review and metaanalysis. 2020;9(1):188. https://doi.org/10.1186/s13643-020-01437-z.

19. Bennet W, Groth CG, Larsson R, Nilsson B, Korsgren O. Isolated human islets trigger an instant blood mediated inflammatory reaction: implications for intraportal islet transplantation as a treatment for patients with type 1 diabetes. Ups J Med Sci. 2000;105(2):125-33.

20. Cheng Y, Wang B, Li H, Zhao N, Liu Y. Mechanism for the instant bloodmediated inflammatory reaction in rat islet transplantation. Transplant Proc. 2017;49(6):14401443.

21. Moll G, Alm JJ, Davies LC, von Bahr L, Heldring N, Stenbeck-Funke L, et al. Do cryopreserved mesenchymal stromal cells display impaired immunomodulatory and therapeutic properties? Stem Cells. 2014;32(9):2430-42

22. Francois M, B Copland I, Yuan S, Romieu-Mourez R, KWaller E, Galipeau J. Cryopreserved mesenchymal stromal cells display impaired immunosuppressive properties as a result of heat-shock response and impaired interferon-gamma licensing. Cytotherapy. 2012;14:147-52.

23. Galipeau J. The mesenchymal stromal cells dilemma-does a negative phase III trial of random donor mesenchymal stromal cells in steroidresistant graft-versus-host disease represent a death knell or a bump in the road? Cytotherapy. 2013;15:2-8.

24. Mohyeddin Bonab M, Yazdanbakhsh S, Lotfi J, Alimoghaddom K, Talebian F, Hooshmand F, et al. Does Mesenchymal stem cell therapy help multiple sclerosis patients? Report of a pilot study Iran. J Immunol. 2007:4(1):50-7.

25. Saeidi M, Masoud A, Shakiba Y, Hadjati J, Mohyeddin Bonab M, Nicknam $\mathrm{MH}$, et al. Immunomodulatory effects of human umbilical cord Wharton's jelly-derived Mesenchymal stem cells on differentiation, maturation and endocytosis of monocyte-derived dendritic cells. Iran J Allergy Asthma Immunol. 2013;12(1):37-49.

26. Zhu M, Heydarkhan-Hagvall S, Hedrick M, Benhaim P, Zuk P. Manual isolation of dipose-derived stem cells from human Lipoaspirates. J Vis Exp. 2013:79:50585.

27. Francis MP, Sachs PC, Elmore LW, Holt SE. Isolating adipose-derived mesenchymal stem cells from lipoaspirate blood and saline fraction. Organogenesis. 2010;6(1):11-4.

28. Squillaro T, Peluso G, Galderisi U. Clinical trials with mesenchymal stem cells: an update. Cell Transplant. 2016;25(5):829-48.

29. Patel DM, Shah J, Srivastava AS. Therapeutic potential of mesenchymal stem cells in regenerative medicine. Stem Cells Int. 2013;2013:496218.

30. de Girolamo L, Lucarelli E, Alessandri G, Avanzini MA, Bernardo ME, Biagi E, et al. Mesenchymal stem/stromal cells: a new "cells as drugs" paradigm. Efficacy and critical aspects in cell therapy. Curr Pharm Des. 2013:19(13):2459-73

31. Bravery CA, Carmen J, Fong T, Oprea W, Hoogendoorn KH, Woda J, et al. Potency assay development for cellular therapy products: an ISCT review of the requirements and experiences in the industry. Cytotherapy. 2013;15(1):9-19.

32. Arzi B, Mills-Ko E, Verstraete FJM, et al. Therapeutic efficacy of fresh, autologous mesenchymal stem cells for severe refractory gingivostomatitis in cats. Stem Cells Transl Med. 2016:5:75-86.

33. Galipeau J. The mesenchymal stromal cells dilemma--does a negative phase III trial of random donor mesenchymal stromal cells in steroidresistant graft-versus-host disease represent a death knell or a bump in the road? Cytotherapy. 2013;15(1):2-8.

34. Terry C, Dhawan A, Mitry RR, Hughes RD. Cryopreservation of isolated human hepatocytes for transplantation: state of the art. Cryobiol. 2006:53(2):149-59. 
35. Chinnadurai R, Garcia MA, Sakurai Y, Lam WA, Kirk AD, Galipeau J, et al. Actin cytoskeletal disruption following cryopreservation alters the biodistribution of human mesenchymal stromal cells in vivo. Stem Cell Rep. 2014;3(1):60-72.

36. François M, Copland IB, Yuan S, Romieu-Mourez R, Waller EK, Galipeau J. Cryopreserved mesenchymal stromal cells display impaired immunosuppressive properties as a result of heat-shock response and impaired interferon- $\gamma$ licensing. Cytotherapy. 2012;14(2):147-52.

37. Fazzina $R$, ludicone P, Fioravanti D, Bonanno G, Totta P, Zizzari IG, et al. Potency testing of mesenchymal stromal cell growth expanded in human platelet lysate from different human tissues. Stem Cell Res Ther. 2016;7(1):122.

\section{Publisher's Note}

Springer Nature remains neutral with regard to jurisdictional claims in published maps and institutional affiliations.
Ready to submit your research? Choose BMC and benefit from:

- fast, convenient online submission

- thorough peer review by experienced researchers in your field

- rapid publication on acceptance

- support for research data, including large and complex data types

- gold Open Access which fosters wider collaboration and increased citations

- maximum visibility for your research: over $100 \mathrm{M}$ website views per year

At BMC, research is always in progress.

Learn more biomedcentral.com/submissions 